\title{
ILLICIT AND NON-ILLICIT DRUGS ASSOCIATED WITH MOTOR CAR HEAD INJURY IN DAMIETTA GOVERNORATE FROM THE IST OF JANUARY 2008 TO 1ST OF JULY 2009
}

\author{
$\mathcal{B} \mathcal{Y}$ \\ Soliman S. Soliman, Foad H. Eldabaah, \\ Mostafa A. Mohamed and Hediah Hindam * \\ Departments of Forensic Medicine and Clinical Toxicology and Neurosurgery* \\ Faculty of Medicine, Al-Azhar University , (New Damietta)
}

\begin{abstract}
A motor vehicle accident is a major public health problem with increasing incidence of mortality and morbidity. Psychoactive drugs, such as amphetamine, cocaine and medicinal drugs increase the risk of road traffic injuries (RTIs). The present work studied the relationship between illicit and non-illicit psychoactive drugs administration and head trauma in motor car accidents in Damietta governorate. The study was conducted from the 1st of January 2008 to 1st of July 2009 and involved 80 cases recruited from the Emergency Department of Al-Azhar University Hospital (New Damietta),in addition to 60 cases as a control group among those admitted to the neurosurgery department with no history of RTIs within the past 6 months. Within one hour after arrival to the emergency room,5ml urine and blood samples were drawn in a sodium fluoride $(\mathrm{NaF})$ contained tubes. Then they were kept at $4-8^{\circ} \mathrm{C}$ for subsequent tests, using radioimmunoassay strips as a preliminary test and a thin layer chromatography (TLC) as a confirmatory tests in the Clinical Toxicology Unit.. Cases and controls were subjected to a standardized questionnaire. Major variables included in the interview were age, sex, smoking, driving behaviors, wearing a protective gear and psychoactive drugs used during the previous month. In each case, all medications administered prior to urine and blood sample collection were recorded. Drug abuse in the present study, was positive in 52 cases (65.0\%) of the studied group compared to 14 cases (23.3\%) of the control group; in the study group, opiates are the most commonly abused (45.0\%) followed by psychoactive drugs (37.5\%), then cannabis (20.0\%) and benzodiazepine (18.8\%), while in the control group, opiates and antihistamines are the most common ( $8.3 \%$ for each one) followed by cannabis and benzodiazepine (5.0\% for each one) and there is a significant difference in the use of cough suppressants, cannabis, opiates, benzodiazepine, psychoactive drugs and drugs co-administration in the study group in comparison to the control group. In conclusion, the present study revealed that illicit and non-illicit drug abuse was associated with motor car accidents regardless the type of the victim (driver, occupant or pedestrian), and the most common drugs used were opiates, psychoactive drugs, cannabis and benzodiazepine.
\end{abstract}




\section{INTRODUCTION}

Vehicle accidents are a major public health problem with increasing contribution to mortality, morbidity and disability. Vehicle trauma is the leading cause of death in young people and one of the commonest causes of death overall (Mackenzie and Fowler, 2000).

The number of people dying from road traffic accidents exceeded 30 million in the last century, and nowadays nearly one million is killed and more than 10 millions are injured annually worldwide (Wang and Jiang, 2003).

The European Union, declared this number of 50,000 fatalities with 1.5 million injuries. In developed countries, the incidence of motor vehicle (MV) accidentrelated injuries and deaths is increasing each year. However, in underdeveloped and developing countries the rates continue to be rise (Krug, 2002).

Nearly, three quarters of deaths resulting from motor vehicle accidents occur in developing countries (Odero et al., 1997). Motor vehicle accidents, falls and assault are the main causes of head trauma. Motor vehicle accidents are also the leading cause of head trauma. In more than half of motor vehicle accidents, the major cause of death is head injuries (Tate et al., 1998).
Psychoactive drugs, such as amphetamine, cocaine and medicinal drugs, increases the risk of RTIs (Movig et al., 2004). These substances impair driving performance by diminishing perception and response to external stimuli (Ramaekers et al., 2004).

Moreover, a combination of two or more psychoactive drugs (Barbone et al., 1998) or psychoactive drugs with alcohol increases the risk of having an accident even further (Movig et al., 2004; Smink et al., 2005).

Existing case-control studies on the relationship between psychoactive drugs and RTI are from developed countries. These studies vary in terms of subject selection, types of specific drug items, cut-off values for positive drug-test results, extraneous variables included and methods of exposure measurements (Drummer et al., 2004; Kasantikul et al., 2005; Engeland et al., 2007).

\section{AIM OF THE WORK}

The aim of the present study is to determine the relationship between illicit and non-illicit psychoactive drugs administration and incidence of head trauma resulting from motor car accidents in Damietta Governorate. 


\section{PATIENTS AND METHODS}

A cases-control study was conducted from the 1st of January 2008 to 1st of July 2009. All 80 cases were recruited from the Emergency Department of Al-Azhar University Hospital (New Damietta). While 60 cases were used as a control group, they were among those admitted to the neurosurgery department with no history of RTIs within the past 6 months. A case was defined as a victim of motor car accident (either a driver or a pedestrian) who sustained a head trauma (whether open or closed) and was admitted to the hospital within 24 hours of the accident. Cases with separate injuries other than the head trauma were excluded from the study.

RTI cases requiring hospitalization initially assessed and treated to stabilize any emergency conditions such as bleeding, severe pain and/or breathing difficulties. In all cases, intravenous line was started at the Emergency Room (ER) and $5 \mathrm{ml}$ of urine and blood samples were obtained concomitantly. Controls were selected from the neurosurgery department who were admitted for other causes than head trauma and who had no history of RTIs within the past 6 months.

Samples were collected and stored below $4^{\circ} \mathrm{C}$. Then they were transferred to the toxicological laboratory. Urine tests were performed using radioimmunoassay strips as a preliminary test and confirmatory tests were done by thin layer chromatography (TLC). Within one hour after arrival in (ER), blood sample was drawn on sodium fluoride $(\mathrm{NaF})$ containing tube. Then it was stored at $4-8{ }^{\circ} \mathrm{C}$ for subsequent laboratory test using thin layer chromatography at the clinical toxicological unit.

Cases and controls were subjected to a standardized questionnaire including age, sex, smoking, wearing a protective gear (helmet, daytime running head light and safety belt), victim types (driver, occupant or pedestrian), then examined clinically with stressing on (heart rate, respiratory rate and blood pressure), Glasgow Coma Scale and the psychoactive drugs used during the previous month were estimated.

In each case, all medications administered prior to urine and blood sample collection were recorded.

\section{STATISTICAL ANALYSIS}

The collected data were organized, tabulated and statistically analyzed using SPSS software computer package version 16 (SPSS Inc. USA). For quantitative data, all the values were expressed as mean \pm standard deviation (SD). For comparison between the two groups, the students $(t)$ test was used. For qualitative data, num- 
ber and percent distribution were calculated and Chi square test $\left(\mathrm{X}^{2}\right)$, was used for comparison between two groups. The value of $\mathrm{P}<0.05$ is considered significant.

\section{RESULTS}

\section{1- Demographic Data :}

As regard the demographic data of the studied cases, 68 were males $(85.0 \%)$ and 12 were females $(15 \%)$ in study group, 45 males $(75 \%)$ and 15 females $(25 \%)$ in control group. There was no significant difference in sex distribution between the studied groups $(\mathrm{P}>0.05)$.

The mean ages of the studied groups are $(38.62 \pm 11.50 \%)$ in study group and $(36.05 \pm 11 \%)$ in control group. There was no significant difference in age distribution between the studied groups $(\mathrm{P}>0.05)$.

The prevalence of smokers, is 50 $(62.5 \%)$ in study group and $24(40.0 \%)$ in control group. There is a significant difference between the studied groups $(P \leq 0.05)$.

The number of victims in motor car accidents are 32 drivers $(40.0 \%), 36$ occupants $(45.0 \%)$ and 12 pedestrians $(15.0 \%)$ and $30 \%$ of them wearing a protective gear (Table 1).

\section{2- Clinical Data :}

Considering the clinical data, there is no significant difference between cases and controls as regard systolic and diastolic blood pressure, respiratory and heart rates $(\mathrm{P}>0.05)$. While there is a significant difference between studied groups as regard Glasgow Coma Scale $\quad(\mathrm{P} \leq 0.05)$ (Table 2).

\section{3- Laboratory Data:}

As regards to the drugs of abuse, it is positive in 52 cases $(65.0 \%)$ of the studied group compared to 14 cases $(23.3 \%)$ of the control group.

In the studied group, opiates are the most common $(45.0 \%)$ followed by psychoactive drugs $(37.5 \%)$, then cannabis $(20.0 \%)$ and benzodiazepine (18.8\%), while in the control group, opiates and antihistamines are the most common $(8.3 \%$ for each one) followed by cannabis and benzodiazepine (5.0\% for each one). The prevalence of multiple drug used $(61.3 \%)$ in the study group and (14.3\%) in the control group and there is a significant difference of cough suppressants, cannabis, opiates, benzodiazepine, psychoactive drugs and drug co-administration in the studied group in comparison to the control group $(\mathrm{P} \leq 0.05)$ (Table 3).

\section{DISCUSSION}

Head injuries and skull fractures are common in clinical medicine and in Forensic practice (Klufas et al., 1996). 
Records of these injuries date to antiquity when Hippocrates and Galen classified different types of skull fractures and developed methods of trephination as a treatment (Kshettrv et al., 2007).

It has been estimated that more than 2 million people are killed in road traffic accidents worldwide each year (Rio and Alvarez, 1999).

Drug of abuse is considered as one of the most serious problems in Egypt that worries the government and the society. It affects mainly the young people within the age of work and productivity (Okashia, 1985).

The objective of this study is to determine the relationship between illicit and non-illicit psychoactive drugs administration and incidence of head trauma resulting from motor car accidents in Damietta Governorate.

As regards the demographic data of the studied cases, sex incidence $(85 \%)$ were males, $(15 \%)$ were females in the study group while $(75 \%)$ were males, and $(25 \%)$ were females in the control group. The majority of male cases are due to the fact that males are more likely to report the use of psychoactive substances and still be accepted in the society (Robinson et al., 1981).
On the other hand, the intense stigma linked to dependent women is attributed to the society view of drug dependence in women as one of moral and sexual degradation, i.e. the behavior that is tolerated in men is considered scandalous for women (Blume, 1991).

Male dominance in drug dependence was also recorded by (Soueif et al., 1987; Amin, and Ahmad, 2003).

In the present study the mean age in years was $(38.62 \pm 11.5)$ in the study group and $(36.05 \pm 11.1)$ in the control group. These finding signify an alarming trend in the prevalence of drug use in such age. Similar result was obtained by Abd ELGawad (2002), who reported that males represent $(76.1 \%)$ of road traffic trauma and the mean age for all cases were $(35.4 \pm 6)$ years.

As regards smoking, it was demonstrated that $(62.5 \%)$ victims involved in motor car accidents were tobacco smokers in the study group and $40.0 \%$ in the control group. This strong association between smoking, substance abuse and motor car accidents was reported by (Soueif et al., 1993; Amin and Ahmad, 2003). Tobacco is a "getaway drugs" i.e. use of these substance is associated with future abuse of illicit drugs and is more daring than nonsmoker in thinking of psychoactive substance, experimenting such substance and 
continuing to take them (O,Donnell, 1979).

The victims of motor car accidents were drivers $(40.0 \%)$; occupants of a motor vehicle $(45.0 \%)$ and pedestrians (15.0\%). $30 \%$ of them wearing a protective gear (Table 1).

Considering the clinical data, there was no significant difference between cases and control groups in systolic and diastolic blood pressure, respiratory rate and heart rate while there was significant increase in Glasgow Coma Scale in study group in comparison to control group and these results are in agreement with Tokdemir et al., 2009), who reported that the majority of included cases in their study were mild according to Glasgow Coma Scale. In addition to (Gerra et al., 2003), who reported significant differences between studied patients as regard clinical data.

As regards the drugs of abuse in the present study, there was significant difference in the use of cough suppressants, cannabis, opiates, benzodiazepine, psychoactive drugs in the study group in comparison to the control group. Woratanarat et al., (2009), reported that amphetamine was found in $16 \%$ in cases and $2 \%$ in controls resulting in 8.9 times increased crash risk. These results are less than those reported in the present study, and this may be attributed to the different pattern of the drug abused between both countries and it may be attributed to the small sample size included in the present study.

In addition, the prevalence of drugs used in the present work is higher 65\% than those of other studies as reported by (Carmen Del Rio and Alvarez, 2000).

The cannabis metabolites were found in $20 \%$ of urine from the study group compared to the control group (5.0\%), these is in contrary to Woratanarat et al. (2009), who reported that the cannabis was found in control group more than cases. This may be attributed to the different inclusion criteria as they examined drivers only in comparison to workers in petrol stations as controls.

In the present study benzodiazepines were frequently detected in the study group (18.8\%) than the control group $(5.0 \%)$. This is in agreement with (Movig et al., 2004; Engeland et al., 2007). who reported that, the benzodiazepine increased the crash risk up to 100 times and the highest potency occurs in the first 7 days after the date of consumption.

Antihistaminics, were detected in the urine of $(5.0 \%)$ in study group and $(8.3 \%)$ in the control group, and these results are in agreement with Woratanarat et al. (2009), who reported that antihistamines was found in $2-4 \%$ of the studies subjects. 
This could be due to a number of factors i.e., intermittent use, short duration of use, avoidance prior to driving or use in a low dosage.

The prevalence of used multiple drugs were $(61.3 \%)$ in the study group and (14.3\%) in the control group. These results are in agreement with (Carmen del Rio and Alvarez, 2000; Movig et al., 2004), since a multiple drug dependence continued to be markedly observed in clinical practice and documented in research studied and the majority of cases were depen- dent on more than one drug either simultaneously (within the same week) or concurrently (within the last year) (De Wet et al., 2004).

In conclusion, the results of the present study revealed that illicit and non-illicit drugs used were associated with motor car accidents regardless the type of the victim (driver, occupant or pedestrian), and the most common used drugs were were opiates, psychoactive drugs benzodiazepine drugs and cannabis. 
Table (1): Comparison between cases and controls as regard demographic data, $(n=140)$.

\begin{tabular}{|c|c|c|c|c|}
\hline \multicolumn{2}{|r|}{ Studied Parameters } & $\begin{array}{l}\text { Study group } \\
(\mathbf{n}=\mathbf{8 0})\end{array}$ & $\begin{array}{c}\text { Control group } \\
(n=60)\end{array}$ & $\begin{array}{c}P \\
\text { value }\end{array}$ \\
\hline \multirow[t]{2}{*}{ Sex } & Male (n., \%) & $68(85.0 \%)$ & $45(75 \%)$ & \multirow[t]{2}{*}{0.089 (NS) } \\
\hline & Female (n.,\%) & $12(15 \%)$ & $15(25.0 \%)$ & \\
\hline \multicolumn{2}{|c|}{ Age (mean $\pm \mathrm{SD})$ in years } & $(38.62 \pm 11.50 \%)$ & $(36.05 \pm 11.10 \%)$ & 0.12 (NS) \\
\hline \multicolumn{2}{|c|}{ Smoking $(\mathrm{n}, \%)$} & $50(62.5 \%)$ & $24(40.0 \%)$ & \\
\hline Victim & $\begin{array}{l}\text { Driver } \\
\text { Occupant } \\
\text { Pedestrian }\end{array}$ & $\begin{array}{l}32(40.0 \%) \\
36(45.0 \%) \\
12(15.0 \%)\end{array}$ & & $0.002(\mathrm{~S})$ \\
\hline \multicolumn{2}{|c|}{ Wearing protective gear } & $24(30.0 \%)$ & & \\
\hline
\end{tabular}

$\mathrm{S}=$ Significant. NS $=$ Non significant. Significant at $\mathrm{P} \leq 0.05$. Non significant difference at $\mathrm{P}>0.05$

Table (2): Clinical data of the study cases, $(n=140)$.

\begin{tabular}{|c|c|c|c|c|}
\hline \multicolumn{2}{|c|}{ Studied Parameters } & $\begin{array}{l}\text { Study group } \\
(\mathbf{n}=\mathbf{8 0})\end{array}$ & $\begin{array}{c}\text { Control group } \\
(n=60)\end{array}$ & $\begin{array}{c}P \\
\text { value }\end{array}$ \\
\hline \multicolumn{2}{|c|}{ Systolic blood pressure (mean \pm SD) } & $133.87 \pm 10.87$ & $131.66 \pm 6.53$ & $0.092(\mathrm{NS})$ \\
\hline \multicolumn{2}{|c|}{$\begin{array}{l}\text { Diastolic blood pressure } \\
(\text { mean } \pm \text { SD) }\end{array}$} & $81.75 \pm 7.16$ & $80.25 \pm 6.05$ & $0.18(\mathrm{NS})$ \\
\hline \multicolumn{2}{|c|}{ Respiratory rate/min } & $18.22 \pm 1.06$ & $17.63 \pm 1.61$ & $0.23(\mathrm{NS})$ \\
\hline \multicolumn{2}{|c|}{ Heart rate/min } & $82.97 \pm 4.70$ & $80.23 \pm 6.04$ & $0.12(\mathrm{NS})$ \\
\hline \multirow{3}{*}{$\begin{array}{l}\text { Glasgow Coma } \\
\text { Scale: }\end{array}$} & Mild (13-15) & $44(55.0 \%)$ & $51(85.8 \%)$ & \multirow{3}{*}{$0.001(\mathrm{~S})$} \\
\hline & Moderate $(9-12)$ & $20(25.0 \%)$ & $8(12.5 \%)$ & \\
\hline & Severe $(3-8)$ & $16(20.0 \%)$ & $1(1.7 \%)$ & \\
\hline
\end{tabular}

$\mathrm{S}=$ Significant. $\mathrm{NS}=$ Non significant. Significant at $\mathrm{P} \leq 0.05$. Non significant difference at $\mathrm{P}>0.05$.

Table (3): The results of laboratory data (as regard the drug of abuse).

\begin{tabular}{|l|c|c|c|}
\hline & $\begin{array}{c}\text { Study group } \\
(\mathbf{n}=\mathbf{8 0})\end{array}$ & $\begin{array}{c}\text { Control group } \\
(\mathbf{n = 6 0 )}\end{array}$ & $\begin{array}{c}\boldsymbol{P} \\
\text { value }\end{array}$ \\
\hline Total cases with drug abuse & $52(65.0 \%)$ & $14(23.3 \%)$ & $0.001(\mathrm{~S})$ \\
\hline Antihistamines & $4(5.0 \%)$ & $5(8.3 \%)$ & $0.36(\mathrm{NS})$ \\
\hline Cough suppressants & $10(12.5 \%)$ & $1(1.7 \%)$ & $0.002(\mathrm{~S})$ \\
\hline Antidepressants & $2(2.5 \%)$ & $1(1.7 \%)$ & $0.68(\mathrm{NS})$ \\
\hline Cannabis & $16(20.0 \%)$ & $3(5.0 \%)$ & $0.001(\mathrm{~S})$ \\
\hline Opiates & $36(45.0 \%)$ & $5(8.3 \%)$ & $0.001(\mathrm{~S})$ \\
\hline Benzodiazepine & $15(18.8 \%)$ & $3(5.0 \%)$ & $0.001(\mathrm{~S}$ \\
\hline Psychoactive drugs & $30(37.5 \%)$ & $2(3.3 \%)$ & $0.001(\mathrm{~S})$ \\
\hline Drugs- co-administration & $32(61.5 \%)$ & $2(14.3 \%)$ & $0.001(\mathrm{~S})$ \\
\hline
\end{tabular}

$\mathrm{S}=$ Significant. NS $=$ Non significant. Significant at $\mathrm{P} \leq 0.05$. Non significant difference at $\mathrm{P}>0.05$ 


\section{REFERENCES}

Abd EL-Gawad, L. (2002) : "Drug abuse among youth in sequestrated areas". A study in Sharabia. The National Review of Criminal Sciences, 45: 116.

Amin, S. A. and Ahmed, A. M. (2003) : "Evaluation of pattern of abused medicinal drug in Menoufiya governorate with special emphasis on the sensitivity of screening and confirmatory tests used in detection". MD thesis (Clin. Toxicology). Faculty of Medicine Menoufiya University.

Barbone, F.; McMahon, A. D.; Davey, P.G.; Morris, A. D.; Reid, I. C.; Mc-Devitt, D. G. and Mac-Donald, T. M. (1998) : "Association of road-traffic accidents with benzodiazepine use". Lancet, 352 : 13311336.

Blume, S. B. (1991) : "Sexuality and stigma: The alcoholic women". Alcohol and Research World,15: 139-146.

Carmen del Rio, M. and Alvarez, F. J. (2000) : "Presence of illegal drugs in drivers involved in fatal road traffic accidents in Spain". Drug Alcohol Depend., 57: 177182.

De Wet, C.; Reed, L.; Glasper, A.; Moran, P. and Grssop, M. (2004) : "Benzodiazepine co-dependence exacerbates the opiate withdrawal syndrome". Drug Alcohol Depend., 5: 3-5.

Drummer, O. H.; Gerostamoulos, J.; Batziris, H.; Chu, M.; Caplehorn, J.; Robertson, M. D. and Swann, P. (2004) : “The involvement of drugs in drivers of motor vehicles killed in Australian road traffic crashes". Accid. Anal. Prev., 36: 239-248.

Engeland, A.; Skurtveit, S. and Morland, J. (2007) : "Risk of road traffic accidents associated with the prescription of drugs. a registry-based cohort study". Ann. Epidemiol., 17: 597-602.

Gerra, G.; Cersini, S.; Zaimovic, A.; Moi, G.; Bussandri, M.; Raggi, M. A. and Molina, E. (2003) : "Neurendocrine and behavioral response to opioid receptorantagonist during heroin detoxification relationship with personality traits". Int. Clin. Psycho-pharmacological, 18: 261-268.

Kasantikul, V.; Ouellet, J. V.; Smith, T.; Sirathranont, J. and Panichabhongse, V. (2005) : "The role of alcohol in Thailand motorcycle crashes". Accid. Anal. Prev., 37: 357-366.

Klufas, R. A.; Hsu. L.; Patel, M. R. and Schwartz, R. B. (1996) : “Unusual manifestations of head trauma". Am. J. Roentgenol.,166: 675-681.

Krug, E. (2002) : “More people die on 
the roads than from malaria. Says WHO Chief". Br. Med. J., 324: 1116.

Kshettrv, V. R.; Mindea, S. A. and Batjer, H. H. (2007) : "The management of cranial injuries in antiquity and beyond". Neurosurg. Focus, 23:38.

Laumon, B.; Gadegbeku, B.; Martin, J. L. and Biecheler, M. B. (2005) : "Cannabis intoxication and fatal road crashes in France. Population based case-control study". BMJ., 331: 1371.

MacKenzie, E. J. and Fowler, C. J. (2000) : Epidemiology. In: Trauma Mattox, K.L.; Feliciano, D.V. and Moore, E.E. (Eds), 4th Ed., New York, P.P. 22 - 28.

Movig, K. L.; Mathijssen, M. P.; Nagel, P. H.; Van Egmond, T.; De Gier, J. J.; Leufkens, H. G. and Egberts, A. C. (2004) : "Psychoactive substance use and the risk of motor vehicle accidents". Accid. Anal. Prev., 36: 631-636.

Odero, W.; Garner, P. and Zwi, A. (1997) : "Road traffic injuries in developing countries. A comparative review epidemiological study". Trop. Med. Int. Health, 2: 445-60.

O,Donnell, J. A. (1979) : Cigarette smoking as a precursor of illicit drug abuse. In : Cigarette Smoking as a Dependence Process, Krasnegor, N. A. (ED),
NIDA research monograph; Rockville, USA, P.P. 30-43.

Okashia, A. (1985) : “Young people and the struggle against drug abuse in Arab World". Bull. Narcotics, 37-76.

Ramaekers, J. G.; Berghaus, G.; van Laar, M. and Drummer, O. H. (2004) : "Dose related risk of motor vehicle crashes after cannabis use". Drug. Alcohol. Depend., 73: 109-119.

Rio, M. C. and Alvarez, F. J. (1999) : "Alcohol use among fatally injured drivers in Spain". Forensic. Sci. Int., 104 : 117125.

Robinson, G. M.; Sellers, E. M. and Janecek, E. (1981) : "Barbiturate and hypno-sedative withdrawal by a multiple oral Phenobarbital loading dose technique". Clinical Pharmacology Therapeutic., 30:71.

Smink, B. E.; Ruiter, B.; Lusthof, K. J.; De Gier, J. J.; Uges, D. R. and Egberts, A.C. (2005): "Drug use and the severity of a traffic accident". Accid. Anal. Prev., 37 : 427-433.

Soueif, M. I.; Darweesh, J. and Taha, H. S. (1987) : "The association between tobacco smoking and use of other psychoactive substance among Egyptian male students". Drug and Alcohol Dependence., 15: 47-56. 
Tate, R. L; McDonald, S. and Lulham, J. M. (1998) : "Incidence of hospitaltreated traumatic brain injury in an Australian community". Aust and New Zeal. J. Public. Healht., 22 : 419-424.

Tokdemir, M.; Kafadar, H.; Deveci, S. E. and Cemil, C. (2009) : "Comparison of the severity of traumatic brain injuries in pedestrians and occupants of motor vehicles admitted to the rat health center: A five-year series in an Eastern Turkish city". Med. Sci. Monit., 15: I1-14.

Wang, Z. and Jiang, J. (2003): “An overview of research advances in road traffic trauma in China". Traffic. Inj. Prev.,4:9-16.

Woratanarat, P.; Ingsathit, A. and Suriyawongpaisal, P. (2009) : “Alcohol, illicit and non-illicit psychoactive drug use and road traffic injury in Thailand: A casecontrol study". Accident Analysis and Prevention, 41: 651-665. 


\section{الأدوية الهشروعة وغير الهشروعة الهرتبطة بحدوث إصابات الرأس أثناء حوادث

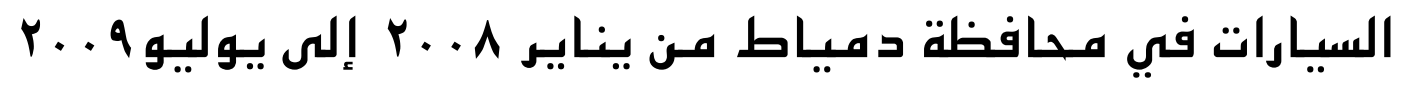
المشتركون فى البحث
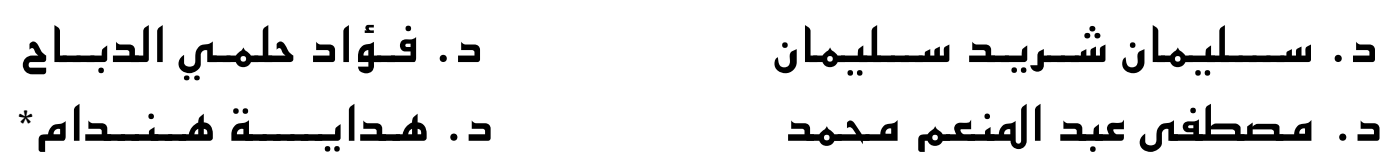

من قسمى الطب الشرعي والسموم الإكلينيكية، جراحة المخ والأعصاب* ، كلية الطب - جامعة الأزهر بدمياط

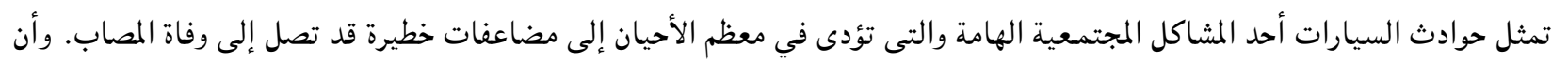

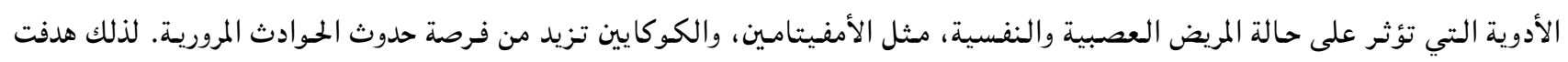

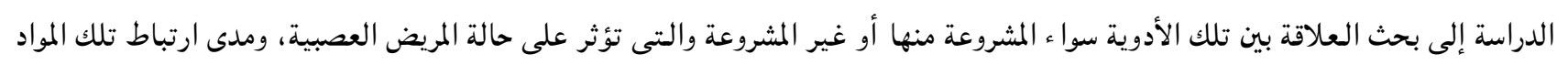

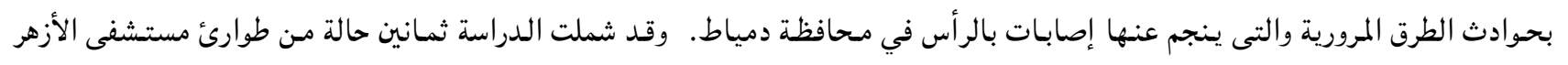

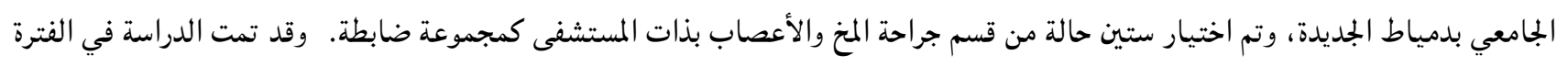

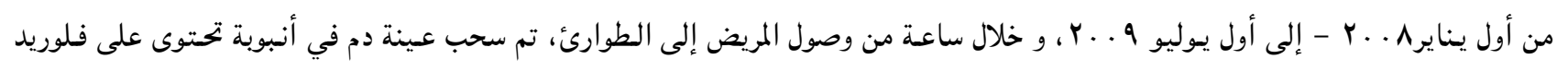

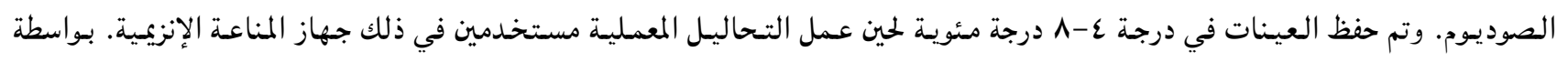

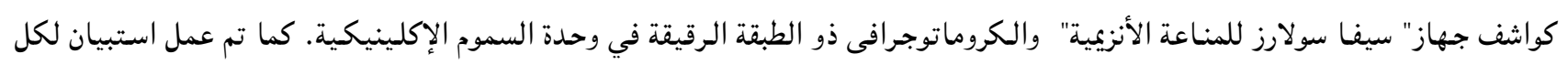

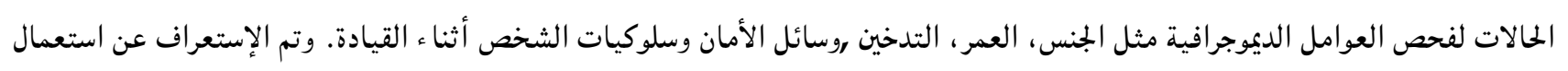

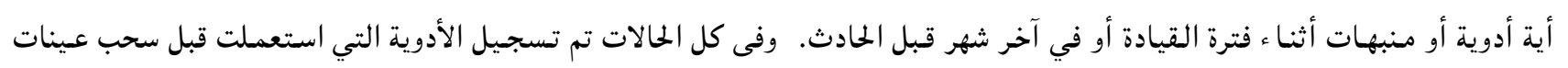

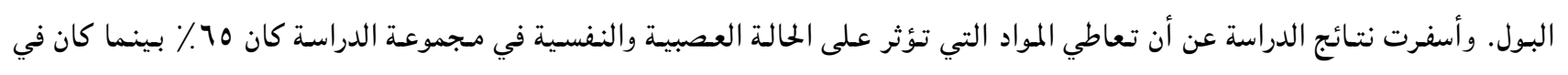

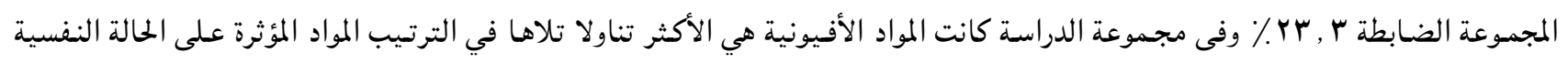

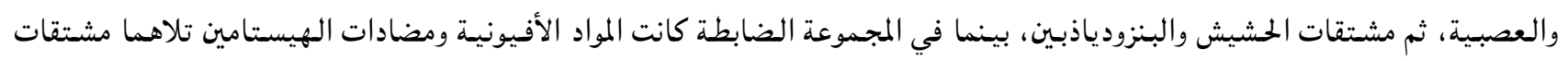

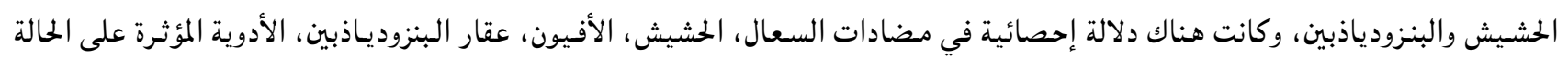

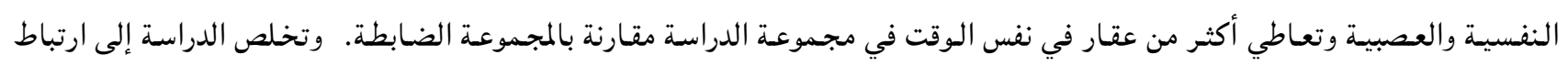

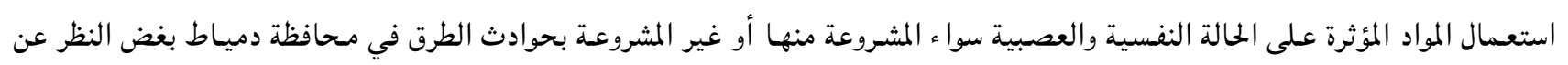

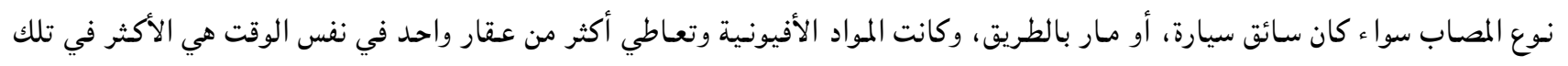
الحالات. 